\title{
Loss of Surround Inhibition and After Sensation as Diagnostic Parameters of Complex Regional Pain Syndrome
}

\author{
Marie Wojcik Wolanin, Robert J. Schwartzman, Guillermo Alexander, John Grothusen
}

Department of Neurology, Drexel University College of Medicine, Philadelphia, USA.

Email: Robert.J.Schwartzman@drexelmed.edu

Received July $6^{\text {th }}, 2012$; revised August $8^{\text {th }}, 2012$; accepted August $15^{\text {th }}, 2012$

\begin{abstract}
Complex Regional Pain Syndrome (CRPS) is a severe chronic pain condition. Patients with CRPS experience allodynia, hyperalgesia, autonomic dysfunction, movement difficulties and dystrophic changes. However other characteristics that may be unique to the pain in CRPS require further study. This study evaluated pain parameters in ninety five subjects composed of three groups: healthy pain free controls, patients with radiculopathy and CRPS patients. Healthy subjects were tested in all four extremities, whereas radiculopathy and CRPS patients were tested only on the most affected extremity. All subjects were tested for the following pain parameters: thermal allodynia, mechanical static and dynamic allodynia, windup, and a hyperalgesic mechanical stimulus. All subjects were also evaluated for autonomic dysfunction, movement disorder and dystrophic skin changes. Statistically significant differences were found between both pain groups and the healthy control subjects as well as between the two pain groups. The finding that statistically differentiated CRPS from radiculopathy and normal controls was pain spread following an algesic mechanical and cold stimulus as well as after sensations to these stimuli. The study demonstrated a simple bedside test that discriminated between CRPS, radiculopathy and healthy control subjects.
\end{abstract}

Keywords: CRPS; Complex Regional Pain Syndrome; Radiculopathy; Pain; After Sensation; Spread; Chronic Pain

\section{Introduction}

Complex Regional Pain Syndrome (CRPS) is a chronic and often disabling pain disorder composed of a constellation of features that include: pain, autonomic dysregulation, edema, motor dysfunction and dystrophic changes [1-3]. It is most often caused by peripheral soft tissue injury, fracture, or nerve injury [2-5]. Emerging evidence suggests that peripheral small sensory nociceptive afferent fibers are causative when no major nerve injury is detectable [6]. Functional MRI and neuropsychological evaluation have demonstrated changes in the pain matrix, autonomic and motor systems as well as perceptual changes of body image over time and with treatment [7-11]. Although a great deal of progress has been achieved in regard to possible underlying causes, such as central sensitization $[12,13]$, and immune mechanisms of induction and maintenance of chronic pain [14-16], many aspects of its pathophysiology remain unknown.

In our prior clinical observations of patients with CRPS, we noticed that an innocuous or slightly algesic mechanical stimulus, such as a pinprick, was perceived not only as severely painful, but also spread beyond the initial territory of the stimulus. In addition, the perception of the pain was maintained as an after sensation following stimulus removal. This study was undertaken to further evaluate the spread of a mechanical stimulus and its after sensation as a clinical test to differentiate CRPS from radiculopathy and normal sensory function.

\section{Methods}

\subsection{Subjects}

Subjects of either gender with a diagnosis of CRPS, cervical or lumbar radiculopathy and healthy and pain-free controls were recruited for this study. The CRPS and some of the radiculopathy subjects were recruited from the neurology clinics of Drexel University School of Medicine. The other radiculopathy subjects were recruited from a neurosurgical practice. Healthy pain-free control subjects were recruited from the general population. All subjects were enrolled after giving informed consent as approved by the Drexel University School of Medicine Institutional Review Boards. 


\subsection{Inclusion Criteria}

Healthy control subjects were accepted into the study if they did not have any acute or chronic pain and could be tested to all modalities on one extremity. The patients in the radiculopathy group had to demonstrate radiologic MRI and EMG as well as clinical evidence of radiculopathy at the tested segmental level. The CRPS patients met all the IASP criteria for Complex Regional Pain Syndrome [1]. Patients in the radiculopathy and CRPS groups had to have a stable pain greater than 4 on a 0 10 Likert numeric rating scale (NRS) where 0 being no pain and 10 the most severe pain imaginable. Subjects eligible for the study had to be between 18 and 65 years of age. They were allowed to continue their pain medication.

\subsection{Exclusion Criteria}

Subjects were excluded if they had significant comorbidities, which could be causing their pain in addition to radiculopathy or CRPS. They also had to be able to cooperate with quantitative sensory testing and clinical evaluation in all four extremities.

\subsection{Pain Parameter Evaluation}

The primary end points were after sensation length to an algesic mechanical (pin prick) and a cold stimulus as well as their spread on an extremity surface.

\subsection{Thermal Allodynia}

The testing of thermal allodynia to cold utilized the metal handle of a standard reflex hammer at room temperature applied to a standard test positions of the forearm (6 inches below the antecubital fossa) and/or mid calf for two seconds. Subjects reported quality of sensation, if it spread and if they continued to feel sensation after stimulus withdrawal. The subjects were asked to describe the sensation of the cold metal in terms of its perception as normal cold, icy cold, burning cold or "paradoxically hot". Spread was measured linearly in centimeters from the sites of application of the stimulus $(0$ to $10 \mathrm{~cm})$. The after sensation was measured from the end of the stimulus in seconds (0 to 30 seconds).

\subsection{Mechanical Allodynia and Hyperalgesia}

An algometer with a $1 \mathrm{~cm}^{2}$ rubber tip FDK 20 (Wagner Insling, Greenwich, CT) was utilized to measure static mechano allodynia. Pressure pain sensitivity was determined in three places in all four extremities in the control subjects or in the most affected extremity in the radiculopathy and CRPS patients. In the upper extremity, subjects were tested supraclavicularly (upper trunk of the brachial plexus primarily C5-C6 roots), 6 inches below the antecubital fossa, and on the middle joint of the third finger. In the lower extremity, measurements were obtained from the posterior popliteal fossa (the bifurcation of the posterior tibial and peroneal nerves, L4-S1 primary roots), the mid calf (6 inches below the popliteal fossa) and the third interphalangeal joint of the great toe. The algometer was pressed until the patient perceived the pressure as painful. The corresponding pressure in kilograms at that point was recorded. Pressure application was stopped at $4 \mathrm{~kg} / \mathrm{cm}^{2}$. It is not clinically possible to distinguish between sensitivity of the skin, muscle or the roots [17] although differences have been demonstrated in these tissues experimentally $[17,18]$. The measurements in the calf were felt to be a measure of the sensitivity of group III, IV muscle afferents [17,18] (nociceptors) and that from the joints C-fiber and A- $\delta$ fiber innervation [19]. Static and mechano allodynia and hyperalgesia elicited with Von Frey hairs were measured in the standard fashion on the extremities at similar locations [20]. A \#5.07 von Frey hair was used to measure skin pressure sensitivity. Measurement of pain was recorded when the filament just bent after being pressed and was rated by the 0 - 10 Likert NRS. Also, Wind-up pain was elicited by 6 depressions of a von Frey hair at half second intervals: the duration of the elicited pain was measured for 30 seconds.

\subsection{Dynamic Mechano Allodynia}

A foam brush (3 inches in diameter) was lightly brushed over the skin at $6 \mathrm{~cm} / \mathrm{sec}$ on the mid-forearm and/or calf. Subjects were asked to evaluate the sensation on the standard Likert numeric NRS of 0 - 10 in regards to the severity of pain it elicited.

\subsection{Algesic Mechano Allodynia}

Pinprick was utilized to measure a sharp mechanical (algesic) stimulus. One pinprick stimulus (a 2 inch pin steel safety pin with nickel plating) was applied (deforming but not puncturing the skin) to the standard test sites in all patient groups. The level of pain to the stimulus (Likert NRS), its spread and after sensations was determined. The spread of the stimulus was measured in one plane (linearly in the extremity) by a centimeter tape, up to $10 \mathrm{~cm}$. After sensation was measured from the end of the application of the stimulus to when it could no longer be felt (up to 30 seconds).

\subsection{Autonomic Parameters}

Dilation of the veins, hyperhidrosis and livedo reticularis (lacy discoloration of the skin in the affected area) were evaluated by observation of the extremities and rated on 
a 0 - 4 scale $(0$ being normal and 4 being severely affected). Skin temperature was evaluated in the forearm and/or calf (standard positions) with a digital infrared thermometer (DermaTemp DT-1001 Infrared Thermographic Digital Scanner, Exergen Corp.). The average of three values from the same location was recorded as the skin temperature.

\subsection{Movement Parameters}

Initiation and facility of movement were assessed by asking the subjects to tap accurately and quickly their index finger to their thumb or wiggle their toes. Response was recorded on a $0-4$ scale: 0 being unable to move the fingers and 4 being normally, accurate and rapid fine finger movement. Spasm, dystonia and tremor were assessed in the affected extremity on a $0-4$ scale. Spasm was scaled with 0 being normal and 4 being severe involuntary contraction of the muscle. Dystonia was scaled with 0 being no dystonia and 4 being the extremity locked in a fixed position. Tremor of the affected extremity was assessed on a scale of 0 - 4 with 0 being absent and 4 being severe, constant and interfering with the function of the extremity. Muscle weakness in the hands was assessed with a Jamar Hand Dynamometer (measured compressive force to $100 \mathrm{~kg}$ ). The subjects were required to squeeze the dynamometer with one hand as hard as possible. Strength was recorded in kilograms. Strength in the lower extremities was tested in the extensor hallucis longus and recorded on a scale of $0-5(0$ being no muscle contraction and 5 being normal strength). Reflexes were evaluated with a Standard Taylor Diagnostic Percussion Reflex Hammer at the biceps brachii and/or patella on a 0 - 4 scale: 0 is are flexia, 1 is a depressed reflex, 2 is a normal reflex, 3 is hyperreflexia and 4 is clonus.

\subsection{Neurogenic and Dystrophic Changes}

Neurogenic edema and erythema were evaluated on a scale of $0-4$ ( 0 being not present and 4 being severe). All subjects were asked if his or her hair grew too quickly or fell out easily. They were similarly queried in regard to nail growth and integrity (splitting and ridging). Responses were recorded as positive or negative. Subjects were also asked about the presence of skin lesions in affected areas [21]. A brief description of the lesions was recorded.

\section{Results}

\subsection{Demographics}

Ninety five subjects were recruited for this study. The number of subjects in each group, their age, gender, duration of illness, overall pain and quality of life evalua- tion scores are tabulated in Table 1 . There were no statistically significant differences $(p>0.05)$ in age or gender ratio between any of the three groups. Both pain groups demonstrated significantly $(\mathrm{p}<0.05)$ greater pain scores and significantly $(p<0.05)$ lower quality of life scores than the healthy control group. However, there were no significant differences $(p>0.05)$ in overall pain or quality of life score between the CRPS and radiculopathy patients. Previous studies have shown that the ratio of women to men who have CRPS is approximately 4:1 [22]; our study also showed a female predominance in the CRPS group.

\subsection{Subject Data}

Parameters evaluating allodynia are tabulated in Table 2. Thermal allodynia to a cold stimulus was quantitatively different between healthy controls, radiculopathy and CRPS patients. $100 \%$ of healthy controls reported the cold metal stimulus to be normally cold. $93 \%$ of the radiculopathy patients reported the cold stimulus to be normally cold while $3 \%$ reported it as warm and $4 \%$ as numb. In the CRPS group, 38\% reported the cold stimulus as a burning sensation, $12 \%$ as an icy-burn, $19 \%$ as icy, $16 \%$ as numb, $3 \%$ as warm and $12 \%$ as normal cold. None of the healthy controls reported spread of the cold stimulus and the average duration of after sensation was $1.46 \mathrm{sec}$. The radiculopathy group also experienced minimal spread of the cold stimulus $(0.13 \mathrm{~cm})$ and a very short duration of after sensation $(7.32 \mathrm{sec})$. The CRPS group had significant spread of the cold stimulus with an average spread of $5.47 \mathrm{~cm}$ and an average duration of after sensation that was $24.38 \mathrm{sec}$.

Table 1. Demographics.

\begin{tabular}{|c|c|c|c|}
\hline & $\begin{array}{c}\text { Healthy } \\
\text { Controls, H }\end{array}$ & Radiculopathy, Rad & CRPS \\
\hline Number of Patients & 35 & $\begin{array}{c}28 \\
\text { Cervical }=6 \\
\text { Lumbar }=22\end{array}$ & 32 \\
\hline Males & 16 & 11 & 9 \\
\hline Females & 19 & 17 & 23 \\
\hline Age (years) & 42.0 & 47.3 & 45.4 \\
\hline $\begin{array}{l}\text { Duration of Illness } \\
\text { (yrs) }\end{array}$ & NA & 4.69 & 9.67 \\
\hline $\begin{array}{l}\text { Overall PainRange } \\
\text { P-Value }\end{array}$ & $\begin{array}{c}0 \\
(0-1) \\
\leq 0.001 \\
(H \text { vs Rad) }\end{array}$ & $\begin{array}{c}8 \\
(4-10) \\
=0.936 \\
\text { (Rad vs CRPS) }\end{array}$ & $\begin{array}{c}8 \\
(4-10) \\
\leq 0.001 \\
\text { (CRPS vs H) }\end{array}$ \\
\hline $\begin{array}{l}\text { Life Evaluation Score } \\
\text { Range } \\
\text { P-Value }\end{array}$ & $\begin{array}{c}10 \\
(8-10) \\
\leq 0.001 \\
(\text { H vs Rad) }\end{array}$ & $\begin{array}{c}5 \\
(0-10) \\
=0.153 \\
(\operatorname{Rad} \text { vs CRPS })\end{array}$ & $\begin{array}{c}4 \\
(0-6) \\
\leq 0.001 \\
(\text { CRPS vs H) }\end{array}$ \\
\hline
\end{tabular}

Age is reported as mean value; overall pain and life evaluation score are reported as median values. 
Table 2. Medians and means of allodynia parameters with standard error and range as well as associated p-values.

\begin{tabular}{|c|c|c|c|c|c|c|}
\hline & $\begin{array}{l}\text { Healthy } \\
\text { Controls, H }\end{array}$ & $\begin{array}{l}\text { P-Value } \\
\text { (H vs. Rad) }\end{array}$ & Radiculopathy, Rad & $\begin{array}{c}\text { P-Value } \\
\text { (Rad vs. CRPS) }\end{array}$ & CRPS & $\begin{array}{c}\text { P-Value } \\
\text { (CRPS vs. H) }\end{array}$ \\
\hline $\begin{array}{l}\text { Thermal Allodynia } \\
\text { Quality }\end{array}$ & $100 \%$ Normal Cold & NA & $\begin{array}{c}93 \% \text { Normal Cold } \\
3 \% \text { Warm } \\
3 \% \text { Numb }\end{array}$ & NA & $\begin{array}{c}38 \% \text { Burn } \\
12 \% \text { Icy-Burn } \\
19 \% \text { Ice } \\
3 \% \text { Warm } \\
16 \% \text { Numb } \\
12 \% \text { Normal Cold }\end{array}$ & NA \\
\hline $\begin{array}{l}\text { Spread }(\mathrm{cm}) \\
\text { Range }\end{array}$ & $\begin{array}{c}0 \\
(0)\end{array}$ & 0.980 & $\begin{array}{l}0.13 \pm 0.10 \\
(0-2.5)\end{array}$ & $<0.0001$ & $\begin{array}{l}5.47 \pm 0.78 \\
\quad(0-10)\end{array}$ & $<0.0001$ \\
\hline $\begin{array}{l}\text { Duration (sec) } \\
\text { Range }\end{array}$ & $\begin{array}{l}1.46 \pm 0.92 \\
(0-30)\end{array}$ & 0.590 & $\begin{array}{l}7.32 \pm 2.23 \\
(0-30)\end{array}$ & $<0.0001$ & $\begin{array}{l}24.38 \pm 2.10 \\
\quad(0-30)\end{array}$ & $<0.0001$ \\
\hline $\begin{array}{c}\text { Dynamic } \\
\text { Mechanical Allodynia } \\
\text { Range }\end{array}$ & $\begin{array}{c}0 \\
(0)\end{array}$ & 1 & $\begin{array}{c}0 \\
(0)\end{array}$ & $<0.001$ & $\begin{array}{c}6 \\
(0-10)\end{array}$ & $<0.001$ \\
\hline $\begin{array}{l}\text { Static Mechanical Allodynia (lbs) } \\
\text { Range }\end{array}$ & $\begin{array}{c}10.48 \pm 0.13 \\
(8.56-11)\end{array}$ & 0.001 & $\begin{array}{l}8.88 \pm 0.44 \\
(2.5-11)\end{array}$ & $<0.0001$ & $\begin{array}{l}3.21 \pm 0.31 \\
(2-10.75)\end{array}$ & $<0.0001$ \\
\hline $\begin{array}{c}\text { Mechanical Joint Allodynia (lbs) } \\
\text { Range }\end{array}$ & $\begin{array}{l}10.58 \pm 0.12 \\
(7.75-11)\end{array}$ & 0.025 & $\begin{array}{l}9.38 \pm 0.48 \\
(2.5-11)\end{array}$ & $<0.0001$ & $\begin{array}{l}3.63 \pm 0.31 \\
\quad(2-8)\end{array}$ & $<0.0001$ \\
\hline $\begin{array}{l}\text { Tinel's Sign (lbs) } \\
\text { Range }\end{array}$ & $\begin{array}{c}10.31 \pm 0.18 \\
(7.75-11)\end{array}$ & 0.0004 & $\begin{array}{l}8.55 \pm 0.48 \\
(4.5-11)\end{array}$ & $<0.0001$ & $\begin{array}{l}3.41 \pm 0.26 \\
\quad(2-7)\end{array}$ & $<0.0001$ \\
\hline $\begin{array}{l}\text { Hyperalgesia with } \\
\text { Von Frey Hair } \\
\text { Range } \\
\text { Von Frev Hair }\end{array}$ & $\begin{array}{c}0 \\
(0-2)\end{array}$ & 1 & $\begin{array}{c}0 \\
(0-3)\end{array}$ & $<0.001$ & $\begin{array}{c}6 \\
(0-10)\end{array}$ & $<0.001$ \\
\hline $\begin{array}{l}\text { Windup Pain } \\
\text { Range }\end{array}$ & $\begin{array}{c}0 \\
(0-4)\end{array}$ & 1 & $\begin{array}{c}0 \\
(0-8)\end{array}$ & $<0.001$ & $\begin{array}{c}8 \\
(0-10)\end{array}$ & $<0.001$ \\
\hline
\end{tabular}

Static mechano allodynia and dynamic mechano allodynia showed similar results with the CRPS subjects reporting pressure turning to pain at much lower pressure values when compared to healthy controls and radiculopathy subjects. In addition, the CRPS group reported the most pain from the von Frey hair when compared to the other two groups.

The healthy controls and the radiculopathy group had no perception of pain from the pinprick stimulus (hyperalgesia). The CRPS group had a median pain level of 8 from the pin prick. The healthy control group had almost negligible spread of the pinprick sensation and no after sensation. The spread of sensation after a pinprick stimulus and the duration of the after sensation differed greatly between radiculopathy patients and CRPS patients $(\mathrm{p}<$ 0.0001) (Table 3, Figure 1). The radiculopathy patients had a longer duration of after sensation to pinprick than control patients, but this was four times less than the CRPS patients $(p<0.0001)$. CRPS patients demonstrated significantly longer after sensations and greatly increased spread as compared to control subjects and radiculopathy patients $(\mathrm{p}<0.0001)$.

Parameters evaluating autonomic, movement, neurogenic edema and erythema are tabulated in Table 4. For autonomic involvement, the healthy controls and the radiculopathy patients both had statistically significantly less $(\mathrm{p}<0.001)$ venous dilation and hyperhidrosis than the CRPS group. Skin temperature was found to be sig- nificantly increased in the healthy control group compared to the radiculopathy and CRPS patients $(\mathrm{p}<$ $0.0001 ; p=0.002$ respectively); however there was no difference in skin temperature between the CRPS group and the radiculopathy group $(\mathrm{p}=0.444)$. The CRPS group demonstrated significantly more livedo reticularis $(p<0.001)$ than controls and radiculopathy patients.

The movement parameters of initiation, spasm, dystonia and tremor were all significantly more affected in CRPS patients than controls or radiculopathy patients ( $p$ $<0.005)$. There was no significant difference $(p=0.154)$ between CRPS and radiculopathy patients in regard to strength of the upper extremities; strength in the lower extremities was significantly different across all three groups with the CRPS patients having the lowest median value ( $p<0.001)$. Reflexes were not significantly different across all three groups, as they all had a median value of $2(\mathrm{p}=0.318)$.

Neurogenic edema and erythema were significantly increased in the CRPS group as compared to the other two groups $(p<0.001)$. Parameters evaluating dystrophic features and skin lesions are tabulated in Table 5. Dystrophic features were mixed with radiculopathy patients reporting the most hair growth, but the CRPS patients reported more hair loss. In addition, both the radiculopathy and CRPS groups reported increased nail growth, but the CRPS group reported the most difficulty with nails breaking easily. Skin lesions were only reported in CRPS 
Table 3. Median Pain Values and Mean Spread and After Sensation Values for Pinprick Parameters.

\begin{tabular}{|c|c|c|c|c|c|c|}
\hline & $\begin{array}{l}\text { Healthy } \\
\text { Controls }\end{array}$ & $\begin{array}{c}\text { P-Value } \\
\text { (Controls vs. Rad.) }\end{array}$ & Radiculopathy (Rad.) & $\begin{array}{c}\text { P-Value } \\
\text { (Rad. vs. CRPS) }\end{array}$ & CRPS & $\begin{array}{c}\text { P-Value } \\
\text { (CRPS vs. Controls) }\end{array}$ \\
\hline $\begin{array}{l}\text { Pinprick Pain } \\
\text { Range }\end{array}$ & $\begin{array}{c}0 \\
(0-2)\end{array}$ & 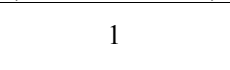 & $\begin{array}{c}0 \\
(0-8)\end{array}$ & $<0.001$ & $\begin{array}{c}8 \\
(0-10)\end{array}$ & $<0.001$ \\
\hline $\begin{array}{c}\text { Pinprick Spread }(\mathrm{cm}) \\
\text { Range }\end{array}$ & $\begin{array}{l}0.01 \pm 0.01 \\
(0-0.25)\end{array}$ & 0.155 & $\begin{array}{l}1.35 \pm 0.52 \\
\quad(0-10)\end{array}$ & $<0.0001$ & $\begin{array}{l}5.75 \pm 0.73 \\
(0-10)\end{array}$ & $<0.0001$ \\
\hline $\begin{array}{c}\text { Pinprick After Sensation (sec) } \\
\text { Range }\end{array}$ & $\begin{array}{c}0 \\
(0) \\
\end{array}$ & 0.019 & $\begin{array}{l}6.61 \pm 2.36 \\
(0-30)\end{array}$ & $<0.0001$ & $\begin{array}{l}24.22 \pm 2.02 \\
\quad(0-30)\end{array}$ & $<0.0001$ \\
\hline
\end{tabular}

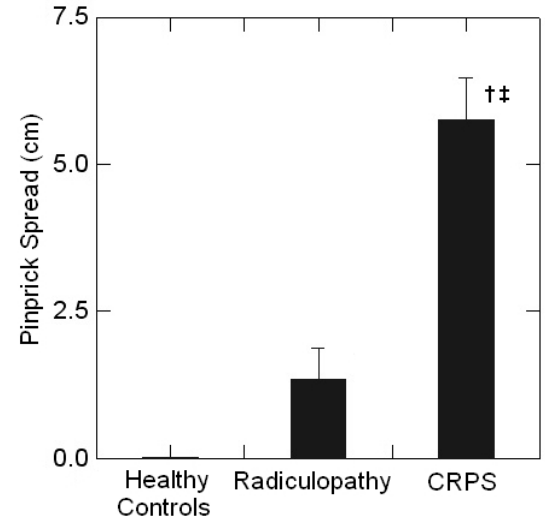

(a)

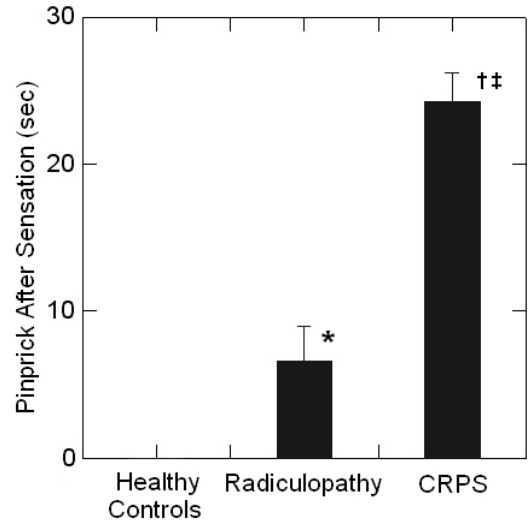

(b)

Figure 1. This figure illustrates the differences in pinprick spread (a) and after sensation (b) between the healthy controls, CRPS and radiculopathy groups. The radiculopathy group demonstrated greater pinprick spread (not significant $\mathrm{p}=\mathbf{0 . 1 5 5}$ ) and significantly greater after sensation $\left({ }^{*} \mathrm{p}<0.05\right)$ than the healthy controls. The CRPS group demonstrated significantly greater spread and after sensation than the healthy controls $\left({ }^{\dagger} p<0.0001\right)$ and the radiculopathy $\left({ }^{\ddagger} p<0.0001\right)$ groups. The CRPS group overwhelmingly felt more pain with the pinprick stimulus, felt the pinprick stimulus point spread the farthest and felt the pinprick stimulus last for the longest period of time.

Table 4. Medians and means of autonomic, movement and neurogenic parameters with standard error and range as well as associated p-values.

\begin{tabular}{|c|c|c|c|c|c|c|}
\hline & $\begin{array}{l}\text { Healthy } \\
\text { Controls, H }\end{array}$ & $\begin{array}{c}\text { P-Value } \\
\text { (H vs. Rad) }\end{array}$ & Radiculopathy, Rad & $\begin{array}{c}\text { P-Value } \\
\text { (Rad vs. CRPS) }\end{array}$ & CRPS & $\begin{array}{c}\text { P-Value } \\
\text { (CRPS vs. H) }\end{array}$ \\
\hline \multicolumn{7}{|l|}{ Autonomic } \\
\hline Veins & 1 & 1 & 1 & $<0.001$ & 3 & $<0.001$ \\
\hline Range & $(0-4)$ & \multirow{3}{*}{1} & $(0-3)$ & & $(1-4)$ & \\
\hline Hyperhydrosis & 0 & & 0 & \multirow[t]{2}{*}{$<0.001$} & 3 & \multirow[t]{2}{*}{$<0.001$} \\
\hline Range & $(0-2)$ & & $(0-2)$ & & $(0-4)$ & \\
\hline Temperature (F) & $88.99 \pm 0.24$ & $<0.0001$ & $86.31 \pm 0.55$ & 0.444 & $87.02 \pm 0.41$ & 0.002 \\
\hline Livedo Reticularis & 0 & \multirow[t]{2}{*}{0.605} & 0 & \multirow[t]{2}{*}{$<0.001$} & 2 & \multirow[t]{2}{*}{$<0.001$} \\
\hline Range & $(0-1)$ & & $(0-2)$ & & $(0-4)$ & \\
\hline Movement Initiation & 4 & \multirow[t]{2}{*}{0.003} & 3 & \multirow[t]{2}{*}{$<0.001$} & 1 & \multirow[t]{2}{*}{$<0.001$} \\
\hline Range & $(3-4)$ & & $(0-4)$ & & $(1-3)$ & \\
\hline Movement Strength Upper Extremity (kg) & $35.77 \pm 2.24$ & \multirow[t]{2}{*}{0.003} & $18.5 \pm 2.32$ & \multirow[t]{2}{*}{0.154} & $8.31 \pm 1.80$ & \multirow[t]{2}{*}{$<0.0001$} \\
\hline Range & $(14.5-66)$ & & $(10-27)$ & & $(0-27)$ & \\
\hline Lower Extremity (kg) & 5 & 0.001 & 4 & 0.001 & 0.5 & $<0.001$ \\
\hline Movement Reflexes & 2 & \multirow[t]{2}{*}{0.318} & 2 & \multirow[t]{2}{*}{0.318} & 2 & \multirow[t]{2}{*}{0.318} \\
\hline Range & $(1-2)$ & & $(0-4)$ & & $(0-4)$ & \\
\hline Movement Spasm & 0 & \multirow[t]{2}{*}{0.001} & 1.5 & \multirow[t]{2}{*}{0.004} & 4 & \multirow[t]{2}{*}{$<0.001$} \\
\hline Range & $(0-1)$ & & $(0-4)$ & & $(0-4)$ & \\
\hline Movement Dystonia & 0 & \multirow[t]{2}{*}{0.046} & 0 & \multirow[t]{2}{*}{$<0.001$} & 3.5 & \multirow[t]{2}{*}{$<0.001$} \\
\hline Range & (0) & & $(0-4)$ & & $(0-4)$ & \\
\hline Movement Tremor & 0 & \multirow[t]{2}{*}{0.228} & 0 & \multirow[t]{2}{*}{$<0.001$} & 2 & \multirow[t]{2}{*}{$<0.001$} \\
\hline Range & (0) & & $(0-4)$ & & $(0-4)$ & \\
\hline Neurogenic Edema & 0 & \multirow[t]{2}{*}{0.152} & 0 & $<0.001$ & 4 & $<0.001$ \\
\hline Range & $(0-3)$ & & $(0-4)$ & & $(0-4)$ & \\
\hline Neurogenic Erythema & 0 & 0.765 & 0 & $<0.001$ & 3.5 & $<0.001$ \\
\hline Range & $(0-1)$ & & $(0-3)$ & & $(0-4)$ & \\
\hline
\end{tabular}


Table 5. Percentage of patients with dystrophic changes and presence of skin lesions.

\begin{tabular}{cccc}
\hline & Healthy & Radiculopathy & CRPS \\
& Controls & & \\
\hline $\begin{array}{c}\text { Dystrophy of Hair } \\
\text { Grows Fast }\end{array}$ & $76 \%$ No & $53 \%$ No & $66 \%$ No \\
& $24 \%$ Yes & $47 \%$ Yes & $34 \%$ Yes \\
Falls Out & $97 \%$ No & $53 \%$ No & $16 \%$ No \\
& $3 \%$ Yes & $47 \%$ Yes & $84 \%$ Yes \\
Dystrophy of Nails: & $84 \%$ No & $43 \%$ No & $41 \%$ No \\
Grow Fast & $16 \%$ Yes & $57 \%$ Yes & $59 \%$ Yes \\
Break Easily & $83 \%$ No & $61 \%$ No & $34 \%$ No \\
& $17 \%$ Yes & $39 \%$ Yes & $66 \%$ Yes \\
Skin Lesions & & & Blisters, \\
& None & None & Discoloration, \\
& & & Ulcers, Open Sores \\
\hline
\end{tabular}

patients and were described as blisters, hyperpigmentation, ulcers and open sores [21].

\section{Discussion}

The most important results of this study are that after sensations and spread of an innocuous and slightly algesic mechanical stimulus clearly discriminate CRPS patients from healthy control subjects and those with radiculopathy. There is an overlap of hyperalgesia as well as mechanical and thermal allodynia among many pain states including neuropathy, plexopathy and radiculopathy so that generalization of these findings to the former two conditions cannot be made [23]. This study also demonstrated significant differences in measures of mechanical sensitivity and motor function but not extremity temperature between CRPS and radiculopathy patients. Autonomic involvement and dystrophic changes in hair and nails were most significant in the CRPS group. Skin lesions were only seen in CRPS patients [21].

The cellular basis of neuropathic pain is incompletely understood. Emerging evidence primarily obtained from experimental pain models demonstrates sensitization of pain transmission neurons (PTNs) following nerve injury [12,24-27]. Physiologic correlates of this sensitization are spontaneous firing, hyperexcitability, enlarged peripheral receptive fields and response to afferents that are usually subthreshold [28,29]. Major physiologic correlates of hyperalgesic states are spontaneous bursts of nociceptive neuronal activity that produce prolonged after discharges (ADs) that out last the period of stimulation [28,30-32].

If spontaneous hyperactivity of wide dynamic range (WDR) PTNs can be modulated, they have an enhanced response to noxious stimuli [33-35]. Non-sensitized WDR and nociceptive specific neurons demonstrate a slow decay of post stimulus discharge following high threshold stimulation $[29,36]$. In the sensitized state, there is a correlation between action potential wind-up and the onset of spinal "plateau potentials" [31]. The intrinsic membrane properties of neurons that demonstrate these potentials are: 1) auto-regenerative discharges that trigger prolonged rhythmic action potentials that are produced within a restricted range of membrane potentials [27,37]; 2) accelerating discharges during intracellular current injection that "plateau" with prolonged stimulation [37-39]; 3) suppression by hyperpolarization [38]; 4) normal discharge expression occurs in a small number of dorsal horn neurons (DHNs) that increases with activation of metabotropic glutamate receptors or blockade of $\mathrm{GABA}_{B}$ receptors [38]. The correlation of "plateau potentials" with long lasting after depolarizations in PTNs is supported by intracellular recordings obtained from in vitro slice preparations of cervical spinal cord Rexed lamina $\mathrm{V}$ WDR neurons. Stimulation of these neurons elicits high frequency responses that sustain a post stimulation discharge for several seconds (i.e. ADs) [40]. The initial calcium influx through voltage gated L-type $\mathrm{Ca}^{2+}$ channels [41] underlies its initial regulation, depolarization and firing acceleration. Its later component maintains high frequency firing and the expression of prolonged after discharges by a $\mathrm{Ca}^{2+}$ activated non-selective $\mathrm{Ca}^{2+}$ $\left(\mathrm{I}_{\mathrm{CAN}}\right)$ current [42]. A small percentage of cells that exhibit "plateau" potentials are also capable of rapidly switching activity. Their firing mode may be determined by somatosensory stimuli [36]. These properties would endow this small percentage of DH nociceptive neurons to prolong a short stimulus to a longer lasting one which may be of significance in nociceptive processing [43].

ADs are considered to be a component of pain perception and maybe what was measured as "after sensation" in the present study $[33,35,44,45]$. A role for calcium currents in the induction and maintenance of neuropathic pain is well documented [46]. Isolated primary sensory neurons from the dorsal root ganglia in rats demonstrating pain behavior following nerve injury have decreased 
endoplasmic reticulum $\mathrm{Ca}^{2+}$ stores [47]. Voltage-activated $\mathrm{I}_{\mathrm{CAN}}$ currents and decreased releasable $\mathrm{Ca}^{2+}$ in axotomized nociceptive neurons cause them to fire repetitively during sustained depolarization due to diminished cytoplasmic $\mathrm{Ca}^{2+}$ transients. The consequences of diminished intracellular $\mathrm{Ca}^{2+}$ concentrations and membrane currents is a decrease of $\mathrm{Ca}^{2+}$ activated $\mathrm{K}^{+}$currents which results in decreased action potential duration and hyperpolarization resulting in neuronal hyperexcitability [41,46-48].

A large body of evidence supports both synaptic activity and immune dependent mechanisms affected by modulation of microglia, astrocytes and PTNs that could cause after sensations that follow a hyperalgesic stimulus in chronic pain patients $[12,15,21,27,47,49,50]$. Phosphokinase $\mathrm{C}$ (epsilon isozyme) expressing interneurons of Rexed lamina $\mathrm{V}$ of the dorsal horn (DH) appear to be particularly important in a subset of NMDA-dependant spinal circuits for maintenance of injury induced chronic pain $[51,52]$ a manifestation of which may be after sensations.

Another mechanism that may account for after sensation in CRPS patients is sensitized peripheral nociceptors recently demonstrated in experimental diabetes [53]. In our study, the other most significant sensory parameter separating control and radiculopathy patients from those with CRPS was spread of a mechanical hyperalgesic stimulus (pin prick). Focus and spatial containment of nociceptive stimuli occur at multiple levels of the neuraxis. At spinal and medullary levels A- $\delta$ afferents, $\mathrm{GABA}_{B}$ and glycinergic neurons effect surround inhibition [12, 54,55]. Serotonergic and noradrenergic descending inhibitory fibers from the descending nociceptive inhibitory controls systems further modulate this inhibition [56]. As noted earlier, a manifestation of central sensitization is enlargement of the receptive fields of PTNs and their depolarization from heterotopic afferents that normally would not discharge them $[12,28,29,57]$. This mechanism could contribute to pain spread in these patients [58, 59].

Neuropsychological studies support plastic changes in both the affective and discriminative components of pain pathways in severe CRPS patients [60]. These patients often describe the affected extremity as feeling smaller or out of place [61]. Stimulating the painful area may be perceived in a different part of the body, such as the face or the contralateral extremity [9]. Proprioceptive deficits occur such that the patient is unaware of the location of the painful part [62]. These psychophysical phenomena have been correlated with dynamic and activity dependent functional MRI changes in the pain matrix [8,63-65]. One patient with generalized CRPS, who was studied with functional MRI, demonstrated false localization from the foot to the face. She demonstrated abnormal activa- tion of the prefrontal cortex neurons that can rapidly shift from low frequency to high frequency firing by stimulation of their receptive fields [66]. This frequency change maybe correlated with spontaneous pain [36]. The prefrontal cortex, primary and secondary somatosensory areas, precuneus, cingulate and insular cortex reverted to normal activation patterns following anesthetic ketamine treatment. She had total relief of pain and false somatotopic localizations to mechanical stimuli [11].

The mechanisms for the greater spread of an algesic mechanical stimulus in CRPS patients as opposed to control subjects and radiculopathy patients are unknown. It is possible that there is a greater immune component in CRPS than radiculopathy. Evidence from the one autopsied patient with CRPS showed generalized (bilateral) spinal cord microglial and astrocytic activation that included the thoracic and cervical cord although the level of injury was at L4-S2 (left gastrocnemius muscle). Neuronal cell loss was seen throughout the spinal cord [50]. Experimental studies in rats with painful mononeuropathy demonstrate primarily segmental spinal level immune activation and loss of DHNs possibly selective for inhibitory GABAergic cells [67-69].

The ease of bedside measurement of both after sensations and spread of an algesic stimulus (pin prick) suggest its use to differentiate radicular from CRPS evoked pain. Prospective blinded studies will be necessary to validate this hypothesis.

\section{Acknowledgements}

This study was supported by gifts from the Tilly Family Foundation for the Study of Complex Regional Pain Syndrome and the Emily Sunstein Foundation for the Study of Neuropathic Pain. All authors declare that there are no financial or other relationships that may lead to a conflict of interest.

\section{REFERENCES}

[1] R. N. Harden and S. Bruehl, "Diagnostic Criteria: The Statistical Derivation of the Four Criterion Factors," In: P. R. Wilson, M. D. Stanton-Hicks and R. N. Harden, Eds., CRPS: Current Diagnosis and Therapy, IASP Press, Seattle, 2005. pp. 45-58.

[2] R. J. Schwartzman, K. L. Erwin and G. M. Alexander, "The Natural History of Complex Regional Pain Syndrome," The Clinical Journal of Pain, Vol. 25, No. 4, 2009, pp. 273-280. doi:10.1097/AJP.0b013e31818ecea5

[3] W. Janig and R. Baron, "Complex Regional Pain Syndrome: Mystery Explained?" The Lancet Neurology, Vol. 2, No. 11, 2003, pp. 687-697.

[4] P. H. Veldman, H. M. Reynen, I. E. Arntz and R. J. Goris, "Signs and Symptoms of Reflex Sympathetic Dystrophy: Prospective Study of 829 Patients," Lancet, Vol. 342, No. 8878, 1993, pp. 1012-1016. 
[5] P. U. Dijkstra, J. W. Groothoff, H. J. ten Duis and J. H. Geertzen, "Incidence of Complex Regional Pain Syndrome Type I after Fractures of the Distal Radius," European Journal of Pain, Vol. 7, No. 5, 2003, pp. 457-462.

[6] A. L. Oaklander and H. L. Fields, "Is Reflex Sympathetic Dystrophy/Complex Regional Pain Syndrome Type I a Small-Fiber Neuropathy?" Annals of Neurology, Vol. 65, No. 6, 2009, pp. 629-638. doi:10.1002/ana.21692

[7] P. Krause, S. Forderreuther and A. Straube, "TMS Motor Cortical Brain Mapping in Patients with Complex Regional Pain Syndrome Type I," Clinical Neurophysiology, Vol. 117, No. 1, 2006, pp. 169-176. doi:10.1016/j.clinph.2005.09.012

[8] B. Pleger, P. Ragert, P. Schwenkreis, A. F. Forster, C. Wilimzig and H. Dinse, et al., "Patterns of Cortical Reorganization Parallel Impaired Tactile Discrimination and Pain Intensity in Complex Regional Pain Syndrome," Neuroimage, Vol. 32, No. 2, 2006, pp. 503-510. doi:10.1016/j.neuroimage.2006.03.045

[9] C. Maihofner, B. Neundorfer, F. Birklein and H. O. Handwerker, "Mislocalization of Tactile Stimulation in Patients with Complex Regional Pain Syndrome," Journal of Neurology, Vol. 253, No. 6, 2006, pp. 772-779. doi:10.1007/s00415-006-0117-z

[10] C. Maihofner, R. Baron, R. DeCol, A. Binder, F. Birklein, G. Deuschl, et al., "The Motor System Shows Adaptive Changes in Complex Regional Pain Syndrome," Brain, Vol. 130, No. 10, 2007, pp. 2671-2687. doi:10.1093/brain/awm131

[11] L. Becerra, R. J. Schwartzman, R. T. Kiefer, P. Rohr, E. A. Moulton, D. Wallin, et al., "CNS Measures of Pain Responses Pre- and Post-Anesthetic Ketamine in a Patient with Complex Regional Pain Syndrome," Pain Medicine, 25 February 2009. doi:10.1111/j.1526-4637.2009.00559.x

[12] C. J. Woolf and M. W. Salter, "Neuronal Plasticity: Increasing the Gain in Pain," Science, Vol. 288, No. 5472, 2000, pp. 1765-1769.

[13] S. S. Dhar and M. T. Wong-Riley, "Coupling of Energy Metabolism and Synaptic Transmission at the Transcriptional Level: Role of Nuclear Respiratory Factor 1 in Regulating Both Cytochrome C Oxidase and NMDA Glutamate Receptor Subunit Genes," The Journal of Neuroscience, Vol. 29, No. 2, 2009, pp. 483-492. doi:10.1523/JNEUROSCI.3704-08.2009

[14] L. R. Watkins and S. F. Maier, "Immune Regulation of Central Nervous System Functions: From Sickness Responses to Pathological Pain," Journal of Internal Medicine, Vol. 257, No. 2, 2005, pp. 139-155. doi:10.1111/j.1365-2796.2004.01443.x

[15] F. Marchand, M. Perretti and S. B. McMahon, "Role of the Immune System in Chronic Pain," Nature Reviews Neuroscience, Vol. 6, No. 7, 2005, pp. 521-532. doi:10.1038/nrn1700

[16] G. M. Alexander, M. J. Perreault, E. R. Reichenberger and R. J. Schwartzman, "Changes in Immune and Glial Markers in the CSF of Patients with Complex Regional Pain Syndrome," Brain, Behavior and Immunity, Vol. 21, No. 5, 2007, pp. 668-676. doi:10.1016/j.bbi.2006.10.009
[17] J. Xu, H. Gu and T. J. Brennan, "Increased Sensitivity of Group III and Group IV Afferents from Incised Muscle in Vitro," Pain, Vol. 151, No. 3, 2010, pp. 744-755. doi:10.1016/i.pain.2010.09.003

[18] J. Xu and T. J. Brennan, "Guarding Pain and Spontaneous Activity of Nociceptors after Skin versus Skin Plus Deep Tissue Incision,” Anesthesiology, Vol. 112, No. 1, 2010, pp. 153-164. doi:10.1097/ALN.0b013e3181c2952e

[19] B. Heppelmann, "Anatomy and Histology of Joint Innervation," Journal of the Peripheral Nervous System, Vol. 2, No. 1, 1997, pp. 5-16.

[20] R. Rolke, W. Magerl, K. A. Campbell, C. Schalber, S. Caspari, F. Birklein, et al., "Quantitative Sensory Testing: A Comprehensive Protocol for Clinical Trials," European Journal of Pain, Vol. 10, No. 1, 2006, pp. 77-88. doi:10.1016/j.ejpain.2005.02.003

[21] G. F. Webster, R. V. Iozzo, R. J. Schwartzman, A. J. Tahmoush, R. L. Knobler and R. A. Jacoby, "Reflex Sympathetic Dystrophy: Occurrence of Chronic Edema and Nonimmune Bullous Skin Lesions," Journal of the American Academy of Dermatology, Vol. 28, No. 1, 1993, pp. 29-32.

[22] M. de Mos, A. G. de Bruijn, F. J. Huygen, J. P. Dieleman, B. H. Stricker and M. C. Sturkenboom, "The Incidence of Complex Regional Pain Syndrome: A Population-Based Study," Pain, Vol. 129, No. 1-2, 2007, pp. 12-20. doi:10.1016/j.pain.2006.09.008

[23] C. J. Woolf and R. J. Mannion, "Neuropathic Pain: Aetiology, Symptoms, Mechanisms, and Management," Lancet, Vol. 353, No. 9168, 1999, pp. 1959-1964. doi:10.1016/S0140-6736(99)01307-0

[24] C. J. Woolf, "Windup and Central Sensitization Are Not Equivalent," Pain, Vol. 66, No. 2-3, 1996, pp. 105-108.

[25] T. Graven-Nielsen and L. Arendt-Nielsen, "Assessment of Mechanisms in Localized and Widespread Musculoskeletal Pain," Nature Reviews Rheumatology, Vol. 6, No. 10, 2010, pp. 599-606. doi:10.1038/nrrheum.2010.107

[26] S. Bruehl, "An Update on the Pathophysiology of Complex Regional Pain Syndrome,” Anesthesiology, Vol. 113, No. 3, 2010, pp. 713-725. doi:10.1097/ALN.0b013e3181e3db38

[27] D. F. Russell and D. K. Hartline, "Bursting Neural Networks: A Reexamination," Science, Vol. 200, No. 4340, 1978, pp. 453-456.

[28] M. L. Sotgiu and G. Biella, "Spinal Expansion of Saphenous Afferents after Sciatic Nerve Constriction in Rats," Neuroreport, Vol. 6, No. 17, 1995, pp. 2305-2308.

[29] M. L. Sotgiu and G. Biella, "Spinal Neuron Sensitization Facilitates Contralateral Input in Rats with Peripheral Mononeuropathy," Neuroscience Letters, Vol. 241, No. 2-3, 1998, pp. 127-130.

[30] G. Guilbaud, J. M. Benoist, A. Levante, M. Gautron and J. C. Willer, "Primary Somatosensory Cortex in Rats with Pain-Related Behaviours Due to A Peripheral Mononeuropathy after Moderate Ligation of One Sciatic Nerve: Neuronal Responsivity to Somatic Stimulation," Experimental Brain Research, Vol. 92, No. 2, 1992, pp. 227-245.

[31] V. Morisset and F. Nagy, "Plateau Potential-Dependent 
Windup of the Response to Primary Afferent Stimuli in Rat Dorsal Horn Neurons," European Journal of Neuroscience, Vol. 12, No. 9, 2000, pp. 3087-3095.

[32] J. Palecek, V. Paleckova, P. M. Dougherty, S. M. Carlton and W. D. Willis, "Responses of Spinothalamic Tract Cells to Mechanical and Thermal Stimulation of Skin in Rats with Experimental Peripheral Neuropathy," Journal of Neurophysiology, Vol. 67, No. 6, 1992, pp. 1562-1573.

[33] J. M. Laird and G. J. Bennett, "An Electrophysiological Study of Dorsal Horn Neurons in the Spinal Cord of Rats with an Experimental Peripheral Neuropathy," Journal of Neurophysiology, Vol. 69, No. 6, 1993, pp. 2072-2085.

[34] I. Omana-Zapata, M. A. Khabbaz, J. C. Hunter and K. R. Bley, "QX-314 Inhibits Ectopic Nerve Activity Associated with Neuropathic Pain," Brain Research, Vol. 771, No. 2, 1997, pp. 228-237.

[35] M. L. Sotgiu, M. Lacerenza and P. Marchettini, "Effect of Systemic Lidocaine on Dorsal Horn Neuron Hyperactivity Following Chronic Peripheral Nerve Injury in Rats," Somatosensory and Motor Research, Vol. 9, No. 3, 1992, pp. 227-233.

[36] C. Monteiro, D. Lima and V. Galhardo, "Switching-On and -Off of Bistable Spontaneous Discharges in Rat Spinal Deep Dorsal Horn Neurons," Neuroscience Letters, Vol. 398, No. 3, 2006, pp. 258-263. doi:10.1016/j.neulet.2006.01.008

[37] R. E. Russo and J. Hounsgaard, "Plateau-Generating Neurones in the Dorsal Horn in an in Vitro Preparation of the Turtle Spinal Cord," The Journal of Physiology, Vol. 493, No. 1, 1996, pp. 39-54.

[38] V. Morisset and F. Nagy, "Modulation of Regenerative Membrane Properties by Stimulation of Metabotropic Glutamate Receptors in Rat Deep Dorsal Horn Neurons," Journal of Neurophysiology, Vol. 76, No. 4, 1996, pp. 2794-2798.

[39] C. Reali and R. E. Russo, "An Integrated Spinal CordHindlimbs Preparation for Studying the Role of Intrinsic Properties in Somatosensory Information Processing," Journal of Neuroscience Methods, Vol. 142, No. 2, 2005, pp. 317-326. doi:10.1016/j.jneumeth.2004.09.006

[40] V. Morisset and F. Nagy, "Nociceptive Integration in the Rat Spinal Cord: Role of Non-Linear Membrane Properties of Deep Dorsal Horn Neurons," European Journal of Neuroscience, Vol. 10, No. 12, 1998, pp. 3642-3652.

[41] A. Fuchs, M. Rigaud, C. D. Sarantopoulos, P. Filip and Q. H. Hogan, "Contribution of Calcium Channel Subtypes to the Intracellular Calcium Signal in Sensory Neurons: The Effect of Injury," Anesthesiology, Vol. 107, No. 1, 2007, pp. 117-127. doi:10.1097/01.anes.0000267511.21864.93

[42] V. Morisset and F. Nagy, "Ionic Basis for Plateau Potentials in Deep Dorsal Horn Neurons of the Rat Spinal Cord," The Journal of Neuroscience, Vol. 19, No. 17, 1999, pp. 7309-7316.

[43] D. Derjean, S. Bertrand, G. Le Masson, M. Landry, V. Morisset and F. Nagy, "Dynamic Balance of Metabotropic Inputs Causes Dorsal Horn Neurons to Switch Functional States," Nature Neuroscience, Vol. 6, No. 3, 2003, pp. 274-281.
[44] C. J. Woolf and A. E. King, "Physiology and Morphology of Multireceptive Neurons with C-Afferent Fiber Inputs in the Deep Dorsal Horn of the Rat Lumbar Spinal Cord," Journal of Neurophysiology, Vol. 58, No. 3, 1987, pp. 460-479.

[45] M. L. Sotgiu, G. Biella and L. Riva, "Poststimulus after Discharges of Spinal WDR and NS Units in Rats with Chronic Nerve Constriction," Neuroreport, Vol. 6, No. 7, 1995, pp. 1021-1024.

[46] Q. H. Hogan, "Role of Decreased Sensory Neuron Membrane Calcium Currents in the Genesis of Neuropathic Pain," Croatian Medical Journal, Vol. 48, No. 1, 2007, pp. 9-21.

[47] M. Rigaud, G. Gemes, P. D. Weyker, J. M. Cruikshank, T. Kawano, H. E. Wu, et al., "Axotomy Depletes Intracellular Calcium Stores in Primary Sensory Neurons," Anesthesiology, Vol. 111, No. 2, 2009, pp. 381-392. doi:10.1097/ALN.0b013e3181ae6212

[48] A. Fuchs, M. Rigaud and Q. H. Hogan, "Painful Nerve Injury Shortens the Intracellular $\mathrm{Ca}^{2+}$ Signal in Axotomized Sensory Neurons of Rats," Anesthesiology, Vol. 107 , No. 1, 2007, pp. 106-116. doi:10.1097/01.anes.0000267538.72900.68

[49] R. J. Schwartzman, G. M. Alexander and J. Grothusen, "Pathophysiology of Complex Regional Pain Syndrome," Expert Review of Neurotherapeutics, Vol. 6, No. 5, 2006, pp. 669-681. doi:10.1586/14737175.6.5.669

[50] L. Del Valle, R. J. Schwartzman and G. Alexander, "Spinal Cord Histopathological Alterations in a Patient with Longstanding Complex Regional Pain Syndrome," Brain, Behavior and Immunity, Vol. 23, No. 1, 2009, pp. 85-91. doi:10.1016/j.bbi.2008.08.004

[51] A. B. Malmberg, C. Chen, S. Tonegawa and A. I. Basbaum, "Preserved Acute Pain and Reduced Neuropathic Pain in Mice Lacking PKCgamma," Science, Vol. 278, No. 5336, 1997, pp. 279-283.

[52] W. J. Martin, A. B. Malmberg and A. I. Basbaum, "PKCgamma Contributes to a Subset of the NMDA-Dependent Spinal Circuits that Underlie Injury-Induced Persistent Pain," The Journal of Neuroscience, Vol. 21, No. 14, 2001, pp. 5321-5327.

[53] D. Fuchs, F. Birklein, P. W. Reeh and S. K. Sauer, "Sensitized Peripheral Nociception in Experimental Diabetes of the Rat," Pain, Vol. 151, No. 2, 2010, pp. 496-505. doi:10.1016/j.pain.2010.08.010

[54] T. Yokota, N. Nishikawa and Y. Nishikawa, "Effects of Strychnine upon Different Classes of Trigeminal Subnucleus Caudalis Neurons," Brain Research, Vol. 168, No. 2, 1979, pp. 430-434.

[55] T. Yokota and Y. Nishikawa, "Action of Picrotoxin upon Trigeminal Subnucleus Caudalis Neurons in the Monkey," Brain Research, Vol. 171, No. 2, 1979, pp. 369-373.

[56] S. Steer, B. Lad, J. A. Grumley, G. H. Kingsley and S. A. Fisher, "Association of R602W in a Protein Tyrosine Phosphatase Gene with a High Risk of Rheumatoid Arthritis in a British Population: Evidence for an Early Onset/Disease Severity Effect," Arthritis \& Rheumatism, Vol. 52, No. 1, 2005, pp. 358-360. doi:10.1002/art.20737 
[57] M. L. Sotgiu, M. Brambilla, M. Valente and G. E. Biella, "Contralateral Input Modulates the Excitability of Dorsal Horn Neurons Involved in Noxious Signal Processes. Potential Role in Neuronal Sensitization," Somatosensory and Motor Research, Vol. 21, No. 3-4, 2004, pp. 211-215. doi:10.1080/08990220400012539

[58] L. S. Sorkin and M. S. Wallace, "Acute Pain Mechanisms," Surgical Clinics of North America, Vol. 79, No. 2, 1999, pp. 213-229.

[59] M. H. Pitcher and F. Cervero, "Role of the NKCC1 CoTransporter in Sensitization of Spinal Nociceptive Neurons," Pain, Vol. 151, No. 3, 2010, pp. 756-762. doi:10.1016/j.pain.2010.09.008

[60] C. Maihofner, H. O. Handwerker, B. Neundorfer and F. Birklein, "Cortical Reorganization during Recovery from Complex Regional Pain Syndrome," Neurology, Vol. 63, No. 4, 2004, pp. 693-701.

[61] G. L. Moseley, "Distorted Body Image in Complex Regional Pain Syndrome," Neurology, Vol. 65, No. 5, 2005, pp. 773. doi:10.1212/01.wnl.0000174515.07205.11

[62] J. Scholz, A. Abele, C. Marian, A. Haussler, T. A. Herbert and C. J. Woolf, et al., "Low-Dose Methotrexate Reduces Peripheral Nerve Injury-Evoked Spinal Microglial Activation and Neuropathic Pain Behavior in Rats," Pain, Vol. 138, No. 1, 2008, pp. 130-142. doi:10.1016/j.pain.2007.11.019

[63] C. Maihofner, H. O. Handwerker, B. Neundorfer and F. Birklein, "Patterns of Cortical Reorganization in Complex Regional Pain Syndrome," Neurology, Vol. 61, No. 12, 2003, pp. 1707-1715.
[64] B. Pleger, M. Tegenthoff, P. Ragert, A. F. Forster, H. R. Dinse and P. Schwenkreis, et al., "Sensorimotor Retuning [Corrected] in Complex Regional Pain Syndrome Parallels Pain Reduction," Annals of Neurology, Vol. 57, No. 3, 2005, pp. 425-429. doi:10.1002/ana.20394

[65] A. Lebel, L. Becerra, D. Wallin, E. A. Moulton, S. Morris, G. Pendse, et al., "FMRI Reveals Distinct CNS processing During Symptomatic and Recovered Complex Regional Pain Syndrome in Children," Brain, Vol. 131, No. 7, 2008, pp. 1854-1879. doi:10.1093/brain/awn123

[66] P. J. Albrecht, S. Hines, E. Eisenberg, D. Pud, D. R. Finlay, M. K. Connolly, et al., "Pathologic Alterations of Cutaneous Innervation and Vasculature in Affected Limbs from Patients with Complex Regional Pain Syndrome," Pain, Vol. 120, No. 3, 2006, pp. 244-266. doi:10.1016/j.pain.2005.10.035

[67] K. A. Moore, T. Kohno, L. A. Karchewski, J. Scholz, H. Baba and C. J. Woolf, "Partial Peripheral Nerve Injury Promotes a Selective Loss of GABAergic Inhibition in the Superficial Dorsal Horn of the Spinal Cord," The Journal of Neuroscience, Vol. 22, No. 15, 2002, pp. 6724-6731. doi:20026611

[68] G. T. Whiteside and R. Munglani, "Cell Death in the Superficial Dorsal Horn in a Model of Neuropathic Pain," The Journal of Neuroscience Research, Vol. 64, No. 2, 2001, pp. 168-173.

[69] A. S. Malik, O. Boyko, N. Atkar and W. F. Young, “A Comparative Study of MR Imaging Profile of Titanium Pedicle Screws," Acta Radiologica, Vol. 42, No. 3, 2001, pp. 291-293. doi:10.1080/028418501127346846 